\title{
Poultice Dosage Form
}

National Cancer Institute

\section{Source}

National Cancer Institute. Poultice Dosage Form. NCI Thesaurus. Code C47913.

A semi-solid composed of a soft, moist mass that is made by wetting an absorbent solid substance. 